\title{
Outcome of Amniotic Membrane Transplant in Persistent Corneal Epithelial Defects
}

\author{
Tiabbah Saleem $^{1}$, Syeda Aisha Bokhari ${ }^{2}$ \\ ${ }^{1}$ Sir Syed College of Medical Sciences, Sir Syed Hospital, ${ }^{2}$ The Eye Center, South City Hospital, Karachi
}

\begin{abstract}
Purpose: To determine the outcome of amniotic membrane transplant in patients with ocular surface disease.

Study Design: Interventional Case series study.

Place and Duration of Study: Layton Rahmatullah Benevolent Trust Eye Hospital, Korangi 21/2, Karachi, from January, 2019 to July 2019.

Methods: Patients with an age range of $20-45$ years, either gender and who had persistent corneal epithelial defects as a consequence of keratitis, chemical injuries, bullous keratopathy and Mooren's ulcers were included. Informed consent was obtained. Preserved amniotic membrane was used in all patients and they were followed at 1 week, 1, 3 and finally at 6 months and results were evaluated in terms of stable, healed and pain-free cornea.
\end{abstract}

Results: Mean age of the patients was $37.94 \pm 6.78$ years. Majority of the patients $(60.0 \%)$ were less than 40 years of age. Out of 58 patients, $45(77.6 \%)$ were males and $13(22.4 \%)$ were females. Mean duration of injury was $7.67 \pm 2.28$ weeks with majority of patients i.e. $62 \%$ were with less than 8 weeks of duration. Most common cause of persistent corneal epithelial defect was bacterial keratitis (17.2\%) followed by vegetative trauma (13.8\%). Successful surgical outcome as healed cornea was observed in $53(91.4 \%)$ patients.

Conclusion: Amniotic membrane transplant is an effective treatment for persistent corneal epithelial defects unresponsive to standard medical treatment. This surgical technique is effective in terms of healing and resolving the inflammation and preserving the useful vision.

Key Words: Persistant corneal epithelial defect, Amniotic Membrane, Bullous keratopathy.

How to Cite this Article: Saleem T, Bokhari SA. Outcome of Amniotic Membrane Transplant in Persistent Corneal Epithelial Defects. Pak J Ophthalmol. 2022, 38 (1): 52-57.

Doi: $10.36351 /$ pjo.v38i1.1340

\section{INTRODUCTION}

Amniotic membrane forms the innermost layer of placenta and consists of a thick basement membrane

Correspondence: Tiabbah Saleem

Sir Syed College of Medical Sciences

Sir Syed Hospital

Karachi

Email:staibbah@gmail.com

Received: October 6, 2021

Accepted: December 7, 2021 that promotes epithelial cell migration and adhesion and an avascular stromal matrix that reduces inflammation, fibrosis and neovascularization. Certain characteristics make the amniotic membrane ideally suited to its application in ocular surface reconstruction. It can be easily obtained and its availability is nearly unlimited. The tissue can be preserved at $-80^{\circ} \mathrm{C}$ for several months, allowing sufficient time to plan surgery or consider a trial of other options. ${ }^{1}$ Amniotic membrane does not express HLA-A, B or DR antigens and hence immunological rejection after its transplantation cannot occur. Transplantation of preserved amniotic membrane can 
be considered one of the major developments in ocular surgery. Although the first ophthalmological use of amniotic membrane documented in the international literature, was almost 70 years ago, amniotic membrane transplantation has been performed in large number of patients since 1995 with promising results. It has been used in the treatment of conjunctival disorders, persistent corneal epithelial defects and painful bullous keratopathy and prone to perforate corneal ulcers. ${ }^{2,3}$ Clinical trials suggest that amniotic membrane transplantation promotes epithelialization and differentiation of the epithelium of the ocular surface. ${ }^{4}$ The most important growth factors that promote wound healing are epidermoid growth factor and keratocyte growth factor, which have been isolated mainly from the amniotic membrane epithelium and stroma..$^{5}$ The normal ocular surface is covered by corneal, limbal and conjunctival epithelial cells. The limbal stem cells give rise to the corneal epithelium and therefore are especially important for maintenance of a smooth, clear corneal surface. These cells together with a stable tear film maintain the health of the ocular surface and therefore, contribute towards improved visual acuity. Damage to these cells from certain systemic inflammatory diseases or primary ocular diseases or trauma such as Stevens Johnson syndrome, ocular cicatricial pemphigoid, rheumatoid arthritis, herpes zoster ophthalmicus, surgically induced neurotrophic keratitis, chemical or thermal injuries and infective keratitis may lead to the state of limbal stem cell deficiency. The result is breakdown of ocular surface and corneal epithelial defects that may become chronic if normal epithelialization process fails. Conjunctival epithelium may replace corneal epithelium resulting in loss of corneal transparency. Chronic inflammation may occur characterized by neovascularization, corneal scarring and opacification, corneal thinning and possible corneal perforation, all of which may lead to loss of visual acuity. ${ }^{6}$ Structural proteins such as laminin and type VII collagen in the amniotic basement membrane explain the observed epitheliotropic effects. Intrinsic neurotropic substances make amniotic membrane an ideal substrate for reconstruction of the epithelium of the ocular surface. Amniotic membrane has been used to treat persistent non-healing corneal ulcers and surface problems with favorable outcomes of healed, stable and pain-free corneal surface. ${ }^{7}$

\section{METHODS}

This study was conducted at LRBT, which is a tertiary care teaching Eye Hospital, Karachi, from January 2019 to June 2019. It was an interventional case series. The sample size was calculated using reference value of expected proportion of successful outcome as $81.8 \%$, keeping confidence level at $95 \%$ and desired precision as $7 \%$. Fifty-eight (58) patients were recruited using non-probability, consecutive sampling. Both male and female with an age range of 20-45 years, who had persistent epithelial defect as a consequence of keratitis, chemical injuries, bullous keratopathy and Mooren's ulcers were included. Information regarding demographic data, history of disease, side involved and ophthalmic examination findings were noted. Examination included visual acuity, slit lamp examination to note extent of damage of corneal epithelial defect measured in two dimensions with $\mathrm{mm}$ scale on slit lamp, limbal ischemia, conjunctival involvement in the form of necrosis, lime deposits, tear film assessment by Schirmer test with and without anesthesia and fundus examination, wherever possible. Exclusion criteria of the study was history of previous ocular surgeries (e.g. cataract surgery) or intraocular injection, intraocular inflammation, penetrating ocular trauma, diabetes, hypertension and patients who lost to follow up before completion of 6 months duration after treatment.

Hospital Ethical Review committee gave the approval for study and informed consent was obtained from all the patients. Preserved amniotic membrane was used in all the patients and they were followed at 1 week, 1, 3 and finally at 6 months and results were evaluated in terms of stable, healed cornea and painfree cornea of level 0 and 1 according to visual analogue scale. At the time of surgery, patient's eye was scrubbed with $10 \%$ povidine solution and draped, eye speculum was placed and $5 \%$ povidine-iodine solution was applied to the ocular surface. Amniotic membrane was thawed at room temperature just before its use, and the membrane was rinsed three times in balanced salt solution. Hand-held corneal trephines of different sizes were used to cut the amniotic membrane according to size of wound, to get regular margins of the applied tissue and for applying neat and equally spaced radial sutures according to anatomical shape of cornea. The membrane was then gently separated from the nitrocellulose paper with blunt forceps. The amniotic membrane was then gently spread on to the ocular surface and trimmed to the 
appropriate size and shape. In cases of corneal pathologies other than chemical injuries, the membrane was secured in place using 10/0 nylon interrupted sutures to the cornea with shiny epithelial surface placing upward. In cases of chemical injuries, as well as Mooren's ulcer (corneal/limbal disease) a membrane much larger than the affected area was needed. In these cases, a combination of interrupted $10 / 0$ nylon sutures to the conjunctiva/episclera and an 11/0 nylon continuous suture (i.e. purse string bedding suture just outside the limbus) was applied. Bandage contact lens (BCL) was routinely used, at the end of the operation, to protect and keep the amniotic membrane in place and for comfort. The sutures and contact lens were removed after 2 to 4 weeks. Recommended post-operative topical treatment consisted of preservative-free antibiotic and corticosteroid drops.

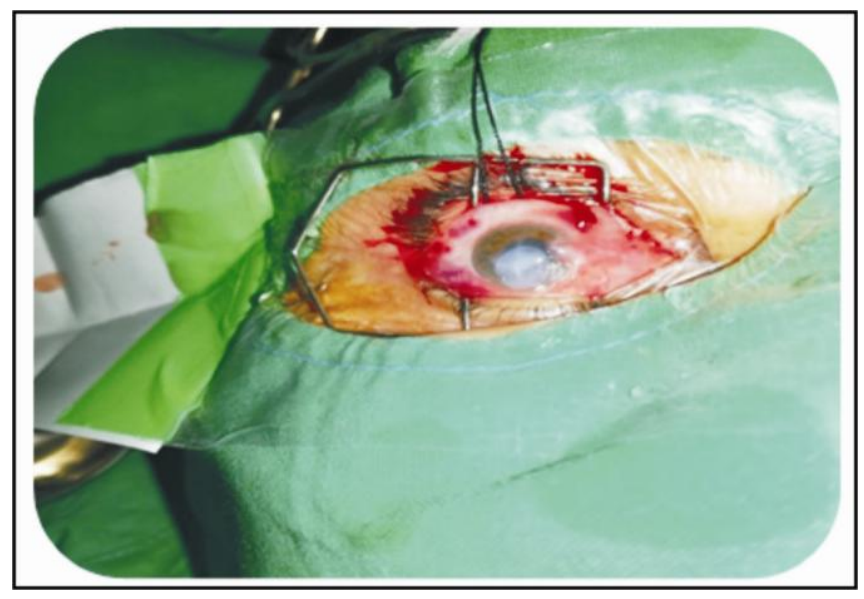

Fig. 1: 1st Layer of Amniotic Membrane (AM) Secured with Continuous Suture.

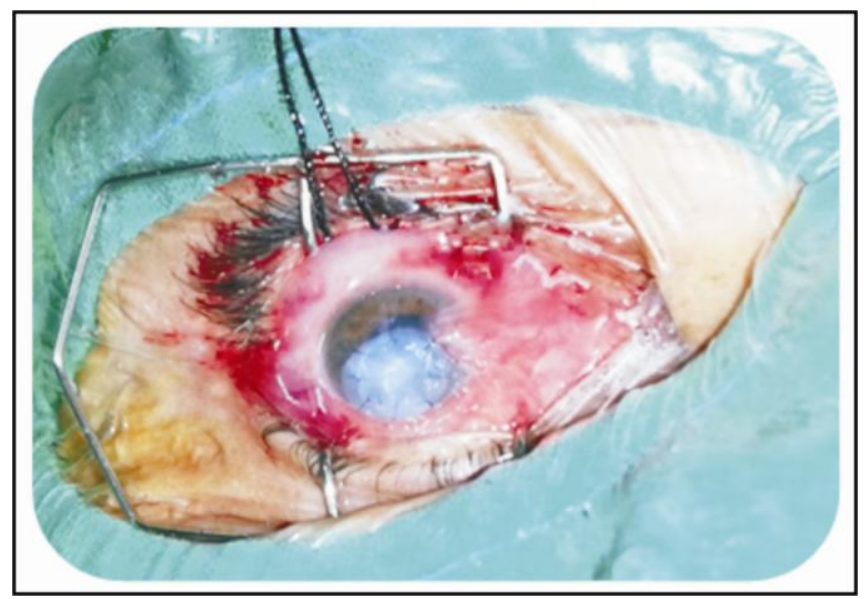

Fig. 2: 2nd Layer of AM with Interrupted Sutures.

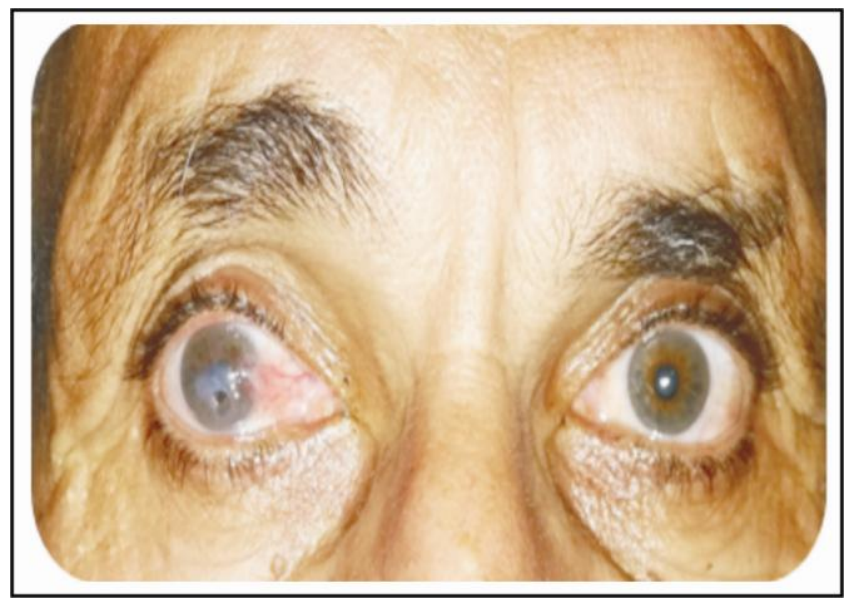

Fig. 3: Rt. Descemdocele.

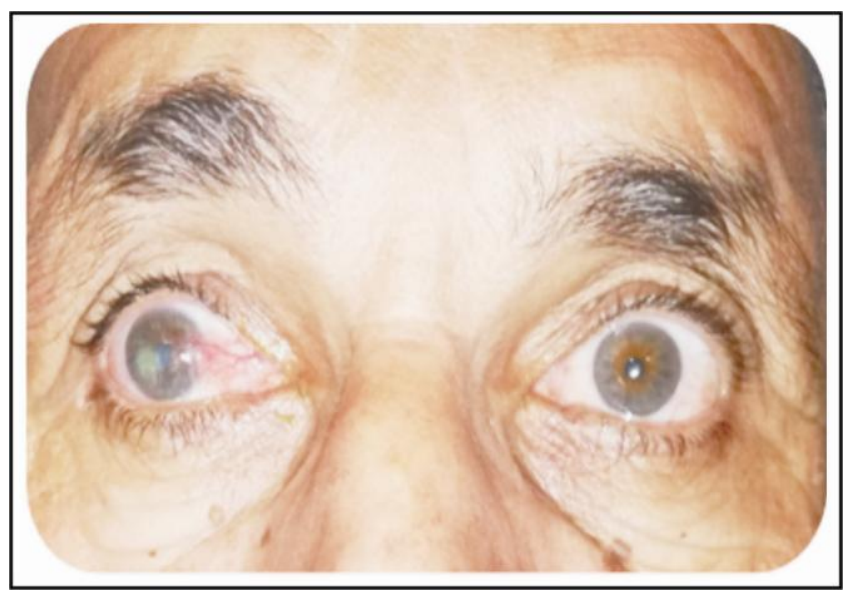

Fig. 4: Decemetocele Resolved (8 Weeks Post-operative).

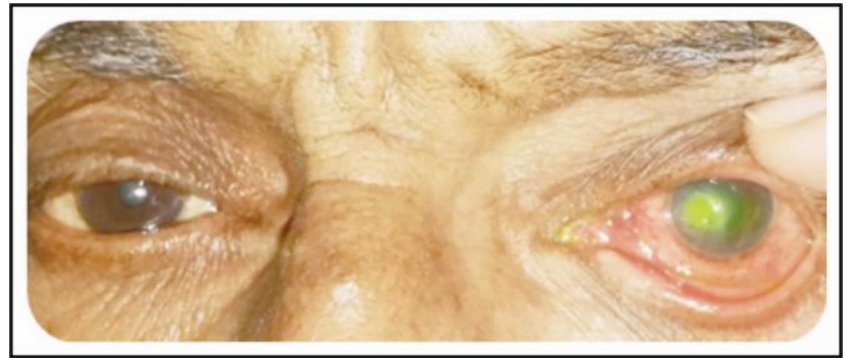

Fig. 5: Pre-operative Left Corneal Epithelial Defect.

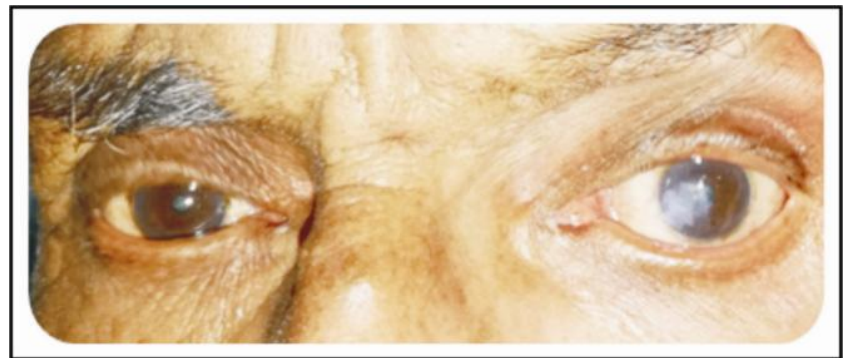

Fig. 6: AM in Place, Conjunctival Inflammation Resolved. 


\section{RESULTS}

The age of patients in this study ranged between 20 to 45 years with mean age of $37.94 \pm 6.78$ years. Majority of the patients $60.0 \%$ were less than 40 years of age. Out of 58patients, $45(77.6 \%)$ were males and $13(22.4 \%)$ were females. Mean duration of symptoms was $7.67 \pm 2.28$ weeks with majority of the patients i.e. $62 \%$ were with less than 8 weeks of duration. Most common cause of persistent corneal epithelial defect was bacterial keratitis (17.2\%) followed by vegetative trauma $(13.8 \%)$. Stable healed cornea was observed in $53(91.4 \%)$ and $54(93.1 \%)$ patients were pain-free after treatment.

Effect modifiers like age, gender, duration of disease and side of eye were controlled through stratification. Post stratification Chi-Square test was applied. P-value $\leq 0.05$ was taken as significant.

Table 1: Frequency distribution of healed cornea according to gender, age, duration and eye.

\begin{tabular}{|c|c|c|c|c|}
\hline \multirow{2}{*}{ Modifiers } & & \multicolumn{2}{|c|}{ Healed Cornea } & \multirow{2}{*}{ p-value } \\
\hline & & Yes & No & \\
\hline \multirow{2}{*}{ Gender } & Male & 40 & 5 & \multirow{2}{*}{0.209} \\
\hline & Females & 13 & 0 & \\
\hline \multirow[b]{2}{*}{ Age } & $<40$ & 32 & 3 & \multirow{2}{*}{0.987} \\
\hline & $>40$ & 21 & 2 & \\
\hline \multirow{2}{*}{$\begin{array}{l}\text { Duration } \\
\text { (weeks) }\end{array}$} & $<8$ & 32 & 4 & \multirow{2}{*}{0.387} \\
\hline & $>8$ & 21 & 1 & \\
\hline \multirow{2}{*}{ Eye side } & Right & 27 & 2 & \multirow{2}{*}{0.640} \\
\hline & Left & 26 & 3 & \\
\hline
\end{tabular}

Table 2: Frequency distribution of pain free cornea according to gender, age, duration and eye.

\begin{tabular}{lllll}
\hline \multirow{2}{*}{ Modifiers } & \multicolumn{4}{c}{ Pain-free cornea } \\
& & Yes & No & \\
\hline \multirow{2}{*}{ Gender } & Male & 43 & 2 & \multirow{2}{*}{0.17} \\
& Female & 11 & 2 & \\
\multirow{2}{*}{ Age (years) } & $<40$ & 32 & 3 & 0.535 \\
Duration & $>40$ & 22 & 1 & \\
(weeks) & $>8$ & 34 & 2 & 0.606 \\
Eye side & Right & 20 & 2 & \\
& Left & 26 & 1 & 0.300 \\
\hline
\end{tabular}

\section{DISCUSSION}

There are multiple ways to manage persistent corneal epithelial defects. Amniotic membrane transplant is one of the successful methods to treat these cases. ${ }^{8-10}$ Our preference to use amniotic membrane transplant was to see its effectiveness in our setup.

Traditional amniotic membrane transplant involves application of sterilized and preserved amniotic membrane patch, cutting it with scissors and applying over the defect site according to the size of defects and securing it with sutures. After that Bandage contact lens (BCL) is applied to allow good approximation of graft to the host surface. We performed amniotic membrane transplant in multi layers depending upon the thinning and severity of defect. Peraka RP et al described the integration of multilayer amniotic membrane graft (mAMG) in the corneal stroma around the full thickness corneal defect. $^{11}$ Similarly, healing effect of amniotic membrane described by Lavaris and colleagues support the effectiveness of mAMG in treatment of corneal epithelial defect. ${ }^{12}$ The application of BCL over the AM provides better approximation and contact of the AM graft with the corneal surface and protects from retraction of graft with blinking and reduces the duration of healing. Xia Zhang and colleagues reported that the healing time of patients with BCL application over amniotic membrane transplant after pterygium excision was $3.43 \pm 1.03$ days, as compared to the group without BCL of $5.13 \pm$ 1.16 days. $^{13}$

Most of the patients included in our study responded within 1 to 2 weeks with healed corneal surface. There was no corneal staining and there was decrease in associated ocular inflammation. The patients with Mooren's ulcer responded with decrease in severity of pain, while surface reconstruction required additional scleral tectonic graft in the areas of severe thinning.

A study conducted by Lee SH supported the idea that amniotic membrane transplantation may be considered as an alternative method for treating persistent epithelial defects and sterile ulceration that are refractory to conventional treatment. He suggested that AM transplant should be considered before planning treatment with conjunctival flaps or tarsorrhaphy. Ten out of 11 patients healed in $3.9 \pm 2.3$ weeks $(P<.01)$ without recurrence for $9.0 \pm 5.9$ months. One patient failed to heal because of preexisting corneal perforation pursuant to severe rheumatoid arthritis. ${ }^{14}$

Hanada K and colleagues performed AMT in three different surgical procedures in 95 patients. AM patch, for the promotion of corneal re-epithelialization was performed in 14 cases, 13 out of them were healed. There were no complications due to the AM transplantation during the course of treatment in any of the 95 cases. $^{15}$ 
Treatment of neuropathic corneal pain (NCP) remains complex and challenging, and involves a long-term combined multistep approach. The selfretained cryop reserved amniotic membrane (PROKERA®, Bio-Tissue, Miami, FL) has been utilized for multiple ocular surface disorders. ${ }^{16}$ Amniotic membrane transplant did not produce successful results in cases of perforated corneas where tarsorrhaphy should be the preferred procedure. ${ }^{17}$

Alina Gheorghe and colleagues reported three cases treated with amniotic membrane transplant. They concluded that the tissue was very conducive to epithelial cell migration and attachment. Keratocytes re-populate the amnion stroma, thus building corneal stromal tissue. The mechanism of action of the membrane was attributed to its physical structure and its molecular constituents. ${ }^{18}$

AMT should be considered for ocular surface reconstruction and also in limbal stem cell deficiency of various severity in conjunction with other novel procedures like kerato-limbal allograft and autograft. Le Q and colleagues concluded that the surgical approaches to treat LSCD (Limbal stem cell deficiency) vary depending on the severity of LSCD. The transplantation of AM alone seems to have limited long term effect. AMT combined with various types of LSC transplantation is commonly performed based on the presumption that AM provides biological and mechanical support, and protection to the transplanted tissues and cells. Although few studies are available but large population studies are lacking to support the efficacy of AMT in LSC transplantation. ${ }^{19,20}$

Limitation of the study was that it was a single centered study. The follow up was of short duration.

\section{CONCLUSION}

Amniotic Membrane Transplant is a very effective treatment modality for persistent corneal epithelial defects not responding to conventional medical treatment. It has additional benefit of reducing associated conjunctival inflammatory response, may reduce the risk of severe limbal cell deficiency, preserving the vision from deterioration and preventing the patient from cosmetically less acceptable procedures. However, wide use of amniotic membrane transplant in occular surface disorders needs to be optimized widely and its efficacy evaluated by conducting wide spread trials.

\section{Ethical Approval}

The study was approved by the Institutional review board/Ethical review board.

(LRBT/FBEH/WEC/3297/17).

\section{Conflict of Interest}

Authors declared no conflict of interest.

\section{REFERENCES}

1. Jirsova K, Jones GL. Amniotic membrane in ophthalmology: properties, preparation, storage and indications for grafting a review. Cell Tissue Bank, 2017; 18 (2): 193-204.

2. Siu GD, Kam KW, Young AL. Amniotic membrane transplant for bullous keratopathy: Confocal microscopy \& anterior segment optical coherence tomography. Semin Ophthalmol. 2019; 34 (3): 163 167.

3. Hossain L, Arifuzzaman M, Diba F, Siddika A, Adnan MH, Akhtar N, et al. Human Amniotic Membrane Preparation, Preservation and Clinical Application Using Various Techniques for the Treatment of Ophthalmic Dysfunctions. Preprints, 2018: 10.0321.v1. Doi: 10.20944/preprints201810.0307.v1

4. Malhotra C, Jain AK. Human amniotic membrane transplantation: different modalities of its use in ophthalmology. World J Transplant. 2014; 4 (2): 111.

5. Koob TJ, Rennert R, Zabek N, Massee M, Lim JJ, Temenoff JS, et al. Biological properties of dehydrated human amnion/chorion composite graft: implications for chronic wound healing. Int Wound J. 2013; 10 (5): 493-500.

6. Tseng SC. HC-HA/PTX3 purified from amniotic membrane as novel regenerative matrix: insight into relationship between inflammation and regeneration. Invest Ophthalmol \& Vis Sci. 2016; 57 (5): ORSFh 18.

7. Kruse FE, Cursiefen C. Surgery of the cornea: corneal, limbal stem cell and amniotic membrane transplantation. Dev Ophthalmol. 2008; 41: 159-170. Doi: $10.1159 / 000131087$.

8. Paolin A, Cogliati E, Trojan D, Griffoni C, Grassetto A, Elbadawy HM, et al. Amniotic membranes in ophthalmology: long term data on transplantation outcomes. Cell Tissue Bank, 2016; 17 (1): 51-58.

9. Monteiro BG, Loureiro RR, Cristovam PC, Covre JL, Gomes JÁ, Kerkis I. Amniotic membrane as a biological scaffold for dental pulp stem cell transplantation in ocular surface reconstruction. Arq Bras Oftalmol. 2019; 82 (1): 32-37. 
10. Korittum AS, Kassem MM, Adel A, Gaith AA, ElHabashi N. Effect of Human Amniotic Membrane Transplantation in Reconstruction of Canine Corneal Wound. Alex. J Vet Sci. 2019; 60 (2).

11. Peraka RP, Kalra P. Multilayered amniotic membrane transplantation in a case of chronic corneal fistula. Br. Med. J Case Rep. 2020; 13 (9): e237369.

12. Lavaris A, Elanwar MF, Al-Zyiadi M, Xanthopoulou PT, Kopsachilis N. Glueless and Sutureless Multi-Layer Amniotic Membrane Transplantation in a Patient With Pending Corneal Perforation. Cureus, 2021; 13 (7): e16678.

doi:10.7759/cureus. 16678

13. Zhang X, Tang Q, Qian XU. Effect of pterygium transplantation combined with amniotic membrane transplantation plus bandage contact lenses for pterygium. Int J Ophthalmol. 2018; 18 (6): 1146-1148.

14. Lee SH, Tseng SC. Amniotic membrane transplantation for persistent epithelial defects with ulceration. Am J Ophthalmol. 1997; 123 (3): 303-312.

15. Hanada K, Nishikawa N, Ishii N, Utsunomiya T, Yoshida A. Amniotic Membrane Transplantation for Corneal and Conjunctival Diseases: Classification of Application and Outcomes from Analysis of 95 cases. Nippon Ganka Gakkai Zasshi. 2017; 121 (4): 359.

16. Alder J, Mertsch S, Menzel-Severing J, Geerling G. Aktuelle und experimentelle Therapieansätze bei neurotropher Keratopathie [Current and experimental treatment approaches for neurotrophic keratopathy]. Ophthalmologe. 2019; 116 (2): 127-137. German. Doi: 10.1007/s00347-018-0843-5. PMID: 30707284.
17. Patel N, Erickson B, Lee WW. Eyelid: Temporary Tarsorrhaphy. In: Rosenberg E., Nattis A., Nattis R. (Eds) Operative Dictations in Ophthalmology. Springer, Cham. 2017: 513-515. https://doi.org/10.1007/978-3319-45495-5_119

18. Gheorghe A, Rosoga AT, Mrini F, Vărgău I, Gherghiceanu F. Various therapies for ocular surface diseases. Rom J Ophthalmol. 2018; 62 (1): 83.

19. Le Q, Deng SX. The application of human amniotic membrane in the surgical management of limbal stem cell deficiency. The Ocular Surface, 2019; 17 (2): 221 229.

20. Qihua Le, Sophie X. Deng. The application of human amniotic membrane in the surgical management of limbal stem cell deficiency. The Ocular Surface, 2019; 17 (2): 221-229.

https://doi.org/10.1016/j.jtos.2019.01.003.

\section{Authors' Designation and Contribution}

Tiabbah Saleem; Senior Registrar: Concepts, Design, Literature search, Data acquisition, Data analysis, Statistical analysis, Manuscript preparation, Manuscript editing, Manuscript review.

Syeda Aisha Bokhari; Consultant Ophthalmologist: Concepts, Design, Data acquisition, Manuscript editing, Manuscript review. 